tinct," and Strickland ${ }^{1}$ while not agreeing with Christophers on this point, after having given the differences in the two larvæ, says "the larva of ludlowi is therefore quite distinct from that of rossi" and in a footnote adds "As a certain amount of confirmation, we may note that if either ludlowi or rossi had hatched out of one of our breeding bottles, on examining the larvæ remaining in the bottles we found in every case, although we need not have expected such favorable evidence, that they were of the type which we now ascribe to the respective species."

The description of Myzomyia parangensis has been comparatively lately published, but specimens were sent to Edwards for comparison before its publication and his verdict was "This is quite unlike any anopheline I have seen before. I suppose it comes nearest to ludlowi."

The status of these species seems to be that the anophelines taken in the Philippines which closely resemble rossi are really indefinita, and that ludlowi, and parangensis are established species.

When insects are connected with the transmission of disease it is doubly important that the nomenclature should be as unclouded as possible, and it is hoped the above points may clear some of the confusion which has existed concerning these species. ${ }^{2}$

\title{
DOES THE HOUSEFLY HIBERNATE AS A PUPA?
}

\author{
By Harold Lyon, \\ Bussey Institution, Harvard University.
}

The following experiments were conducted during the past winter to determine if it were possible for the housefly to overwinter in the pupal stage. Thirty-seven lots were obtained, each

\footnotetext{
${ }^{1}$ Strickland, C., The Comparative Morphology of the Anophelines Nyssomyzomyia ludlowi Theob. and Nyssomyzomyia rossi Biles. Bull. Ento. Research., Vol. V, Pt. 4, March, 1915.

2 Since this article was sent to the publisher Mr. Edwards writes that "the name christophersi must be replaced by minimus, Theob. (described rather inaccurately from Hong Kong in 1901.)" The species was afterward referred to Pyretophorus, under which genus it is placed in Bull. No. 4, Surgeon General's Office, p. 46.
} 
consisting of one hundred pupæ. These were buried in wet and dry sand, wet and dry loam, wet and dry horse manure and in leaf mould. These materials, together with the pupæ, were placed in large glass jars, covered with cloth and the whole divided into four series. One series was placed out of doors under sheltered conditions, one under exposed conditions, another in an unused greenhouse and the last in the basement of a large stone building.

The experiments were started on October 19, 1914, and flies continued to emerge till December first from the jars stored in the basement. Two hundred and ten adults emerged from nine hundred pupæ, the greatest number coming from the dry manure, wet sand and wet manure. The temperature of the basement was about $60^{\circ} \mathrm{F}$. during the entire winter.

In the unused greenhouse, which was somewhat warmer than out of doors, three hundred and sixty-four adults emerged from eleven hundred pupæ, the greatest numbers emerging from wet manure and dry sand. The last adult emerged on November twenty-fourth.

No adults emerged from the jars out of doors, although the weather was very mild, with the temperature only slightly lower than that in the unused greenhouse.

Observations were made daily and no adults emerged after December first. On June 23, 1915, the jars were opened and the contents examined. No parasites or fungi were found and the pupæ appeared perfectly normal, but on being broken open they were found to have completely dried out. This condition was observed in all the jars.

The results of these experiments, which represented quite natural conditions and the especially favorable conditions of the basement of the building, seem to indicate that the housefly can not easily overwinter as a pupa, although it can emerge until the middle of winter. It would seem, therefore, that the appearance of seemingly freshly-emerged adults in any considerable numbers during late winter and early spring should be accounted for in some other way. 

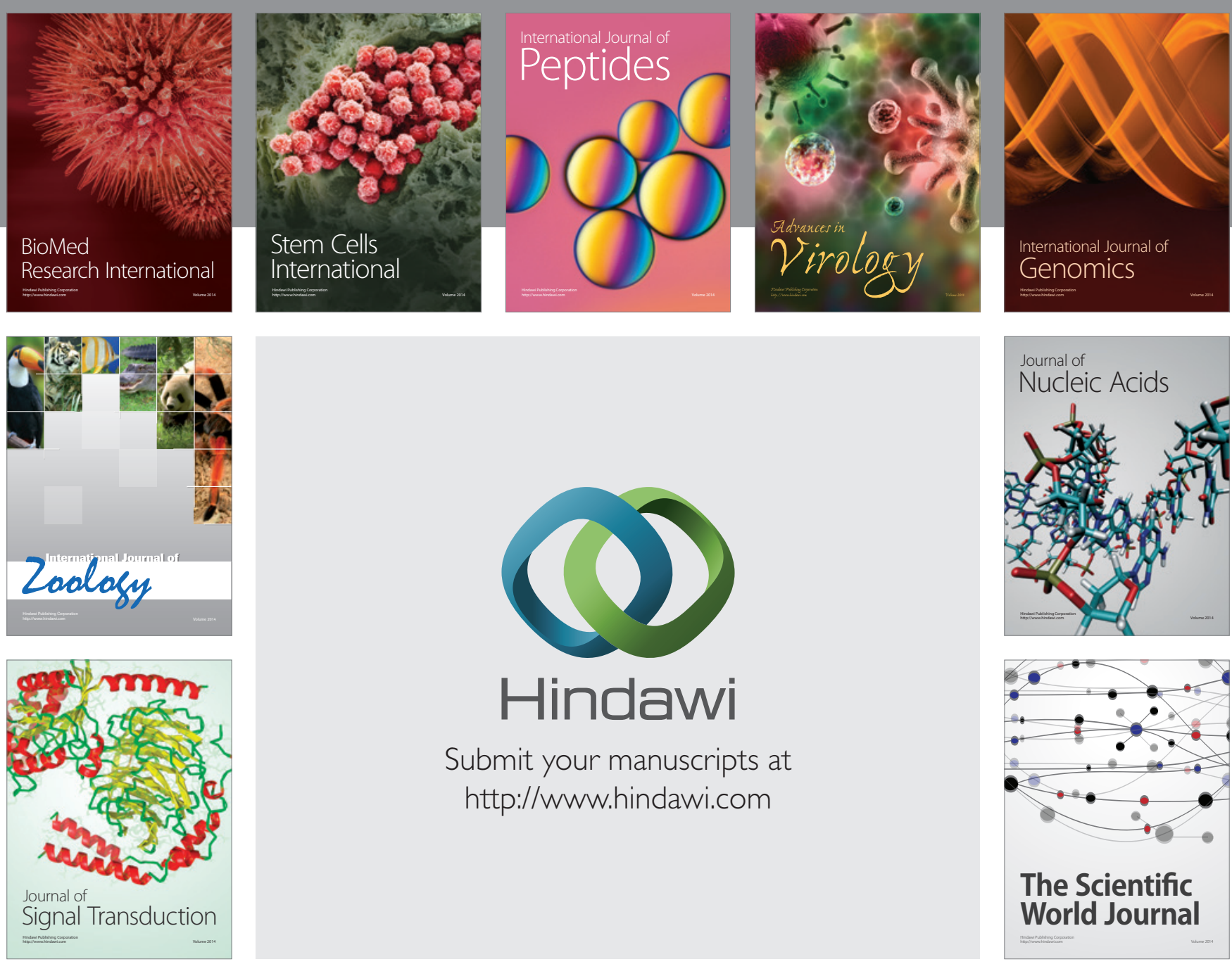

Submit your manuscripts at

http://www.hindawi.com
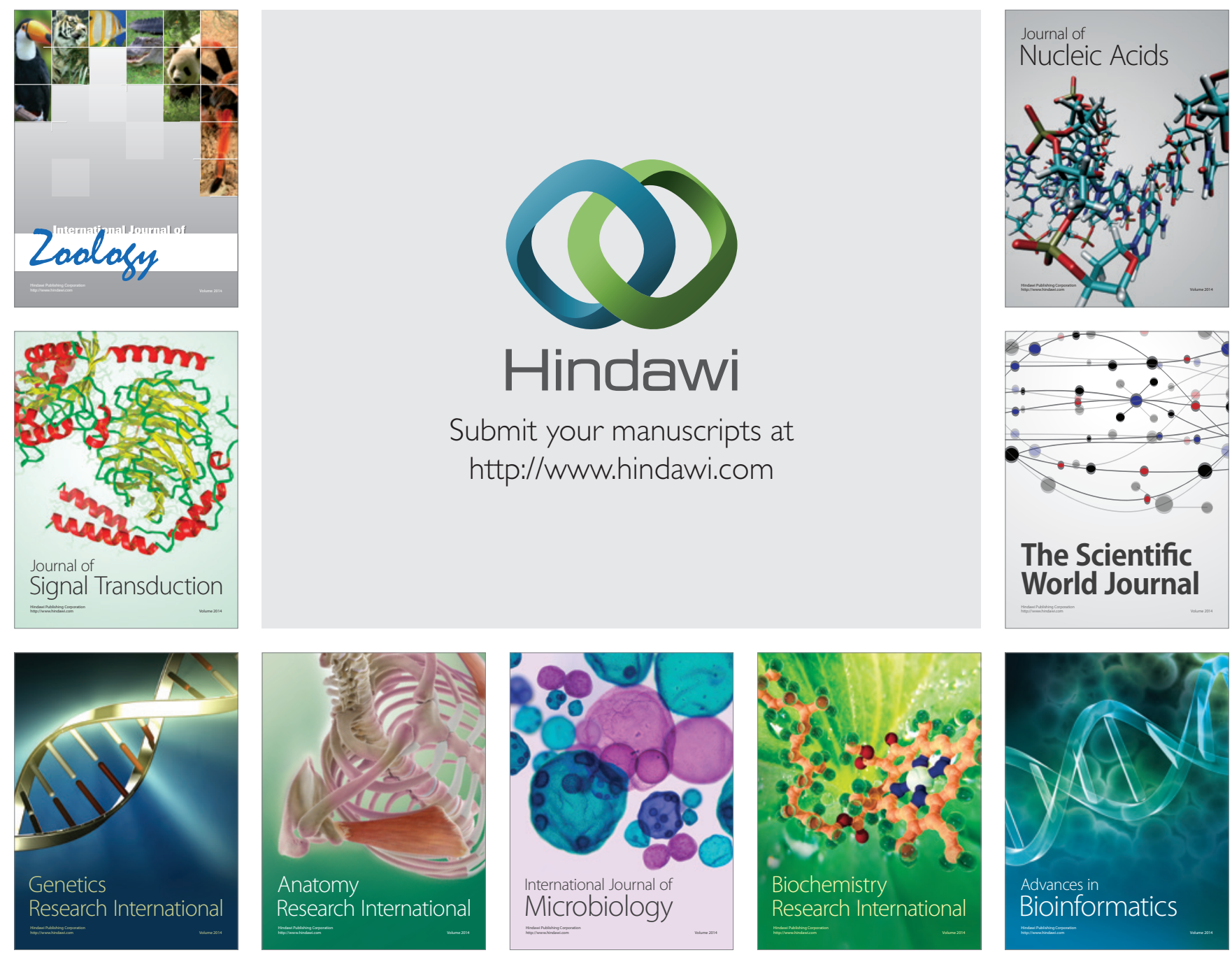

The Scientific World Journal
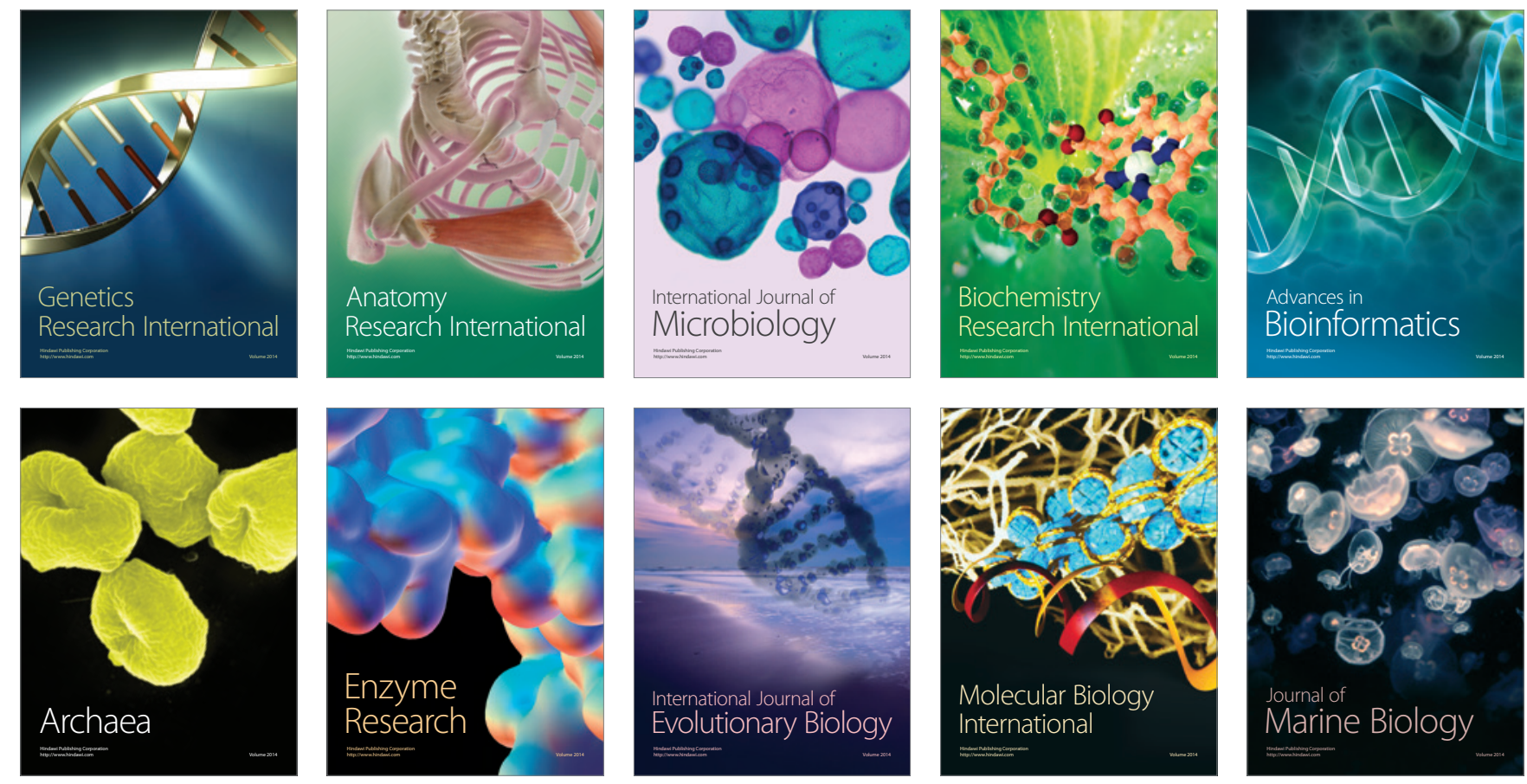